\title{
Excited-State Intramolecular Hydrogen Transfer of Compact Molecules Controls Amyloid Aggregation Profiles
}

Mannkyu Hong, ${ }^{\dagger,+\|} \|$ Mingeun Kim, ${ }^{\dagger, \|}$ Jiwon Yoon, ${ }^{\S}$ Seung-Hee Lee, ${ }^{*, \S}$ Mu-Hyun Baik, ${ }^{*,+\neq}$ and Mi Hee Lim*,ं

'Department of Chemistry, Korea Advanced Institute of Science and Technology (KAIST), Daejeon 34141, Republic of Korea

'Center for Catalytic Hydrocarbon Functionalizations, Institute for Basic Science (IBS), Daejeon 34141, Republic of Korea

${ }^{\S}$ Department of Biological Sciences, Korea Advanced Institute of Science and Technology (KAIST), Daejeon 34141, Republic of Korea

*To whom correspondence should be addressed: miheelim@kaist.ac.kr, mbaik2805@kaist.ac.kr, and shlee1@kaist.ac.kr

$\|$ These authors contributed equally to this work. 


\begin{abstract}
Designing new chromophores by tuning their molecular structures and optimizing their photophysical properties leads to suitable photochromic features. Herein, we report a series of anthraquinone (AQ)-based photosensitizers that undergoes excited-state intramolecular hydrogen transfer and effectively oxidizes amyloidogenic peptides, which significantly affects the subsequent aggregation pathways. DFT calculations showed that the appropriate position of the hydroxyl groups in the $\mathbf{A Q}$ backbone and the consequent intramolecular hydrogen transfer can facilitate the energy transfer to triplet oxygen. Biochemical and biophysical investigations confirmed that these photoactive chemical reagents are able to oxidatively modify both metal-free amyloid- $\beta(A \beta)$ and metal-bound $A \beta$, thereby redirecting their on-pathway aggregation into offpathway as well as disassembling their pre-formed aggregates. Moreover, the in vivo histochemical analysis of $A \beta$ species produced upon photoactivation of the most promising candidate demonstrated that they do not aggregate into toxic oligomeric or fibrillar aggregates in the brain. Overall, our combined computational and experimental studies validate a light-based approach for designing small molecules as chemical reagents targeting and controlling amyloidogenic peptides associated with neurodegenerative disorders.
\end{abstract}




\section{INTRODUCTION}

Numerous chemical reagents were developed for photodynamic therapy (PDT) since the ground breaking discovery that eosin can be used to treat skin tumors. ${ }^{1-7}$ Commercialized drugs, such as porfimer sodium (Photofrin), 5-aminolevulinic acid (ALA), methyl aminolevulinate (MAL), and methyl aminooxopenoat (MAOP), demonstrated the power of using light to target internal and skin tumors. $^{8-10}$ In general, PDT relies upon generating reactive oxygen species (ROS) upon photoactivation that can damage lipids, proteins, and nucleic acids, eventually triggering cell death or protein inactivation. ${ }^{1,11,12}$ Recently, ROS-induced oxidative modifications of amyloid- $\beta$ (AB) peptides have been recognized as an effective method for controlling their aggregation pathways that are directly linked to the pathology of Alzheimer's disease (AD).$^{13}$ Oxidation of $A \beta$ peptides with photosensitizers ${ }^{14}$ or redox-active molecules ${ }^{15-20}$ may alter their abnormal assembly and improve cognitive defects in $A D$ transgenic mice. A variety of photosensitizers ranging from fullerene $^{21}$ or porphyrin-based ${ }^{22}$ macromolecules, organometallic complexes, ${ }^{23-28}$ nanoparticles, ${ }^{29,30}$ and organic molecules ${ }^{31-34}$ were designed to modulate the aggregation of $A \beta$. Despite their remarkable potential, the complexity of synthesis, low permeability of the blood-brain barrier (BBB), ${ }^{35,36}$ and the potential risk in toxicity37-39 remain significant hurdles to overcome.

We questioned if small organic photosensitizers carrying simple functionalities such as hydroxyl and carboxyl groups can oxidatively modify both metal-free $A \beta$ and metal-bound $A \beta$ (metal-A $\beta$ ) and alter their aggregation profiles. As shown in Figure $1 \mathrm{a}$, we rationally selected a series of anthraquinone ( $\mathbf{A Q}$ )-based compounds and tested their capacity to oxidize metal-free $A \beta$ and metal- $A \beta$ upon photoirradiation and, consequently, vary their aggregation. In addition, the detailed mechanism for such reactivity was determined. Moreover, the aggregation behaviors of $A \beta$ species produced upon light activation of the most promising molecule were probed in vivo. Collectively, our studies demonstrate that compact molecules with proper structural and photophysical features can be developed for manipulating $A \beta$ aggregation with light.

\section{RESULTS AND DISCUSSION}

AQ-based dyes have been used as photosensitizers for various applications such as photovoltaics, ${ }^{40}$ photocatalysts, ${ }^{41-43}$ photoactive peptides, ${ }^{44}$ and cell imaging $;{ }^{45}$ thus, we chose the $A Q$ backbone to identify effective photosensitizers that can oxidatively modify $A \beta$ peptides. As displayed in Figure 1a, a series of $\mathbf{A Q}$-based molecules with simple structural variations composed of only three basic carbon, hydrogen, and oxygen atoms was selected for this work. Based on the parent structure $\mathbf{9 , 1 0 - A Q}$, the hydroxyanthraquinone derivatives were classified into 
(a)

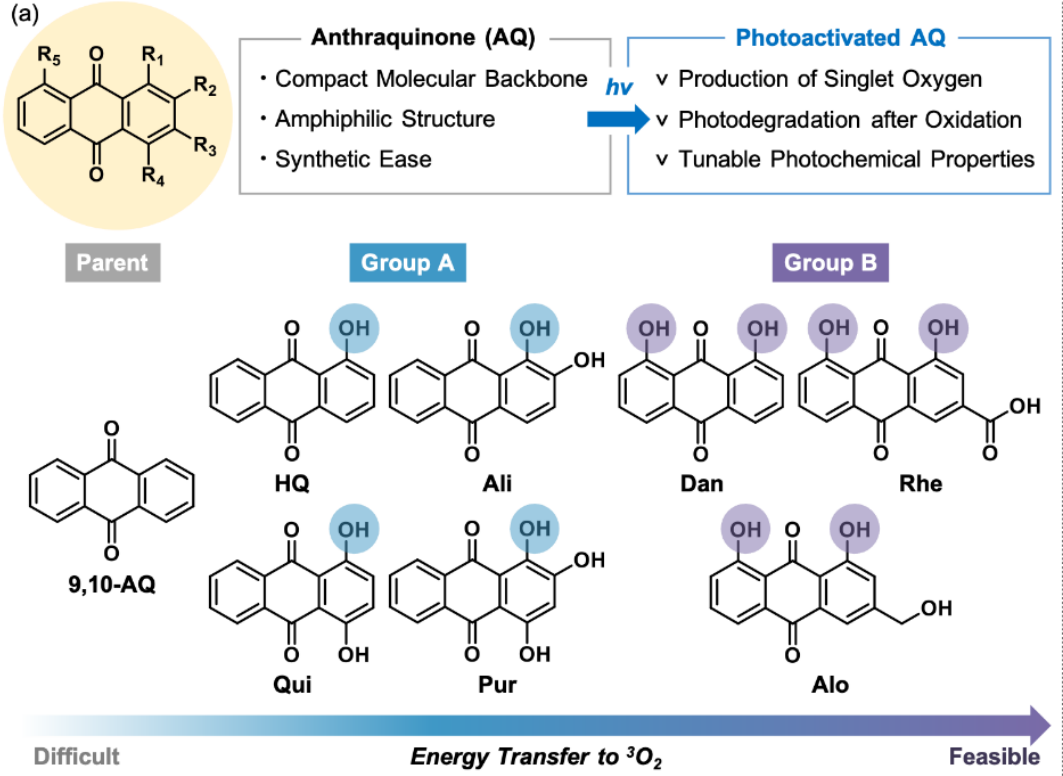

(b)

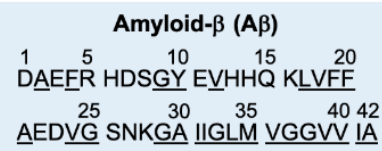

(c) On-pathway Aggregation

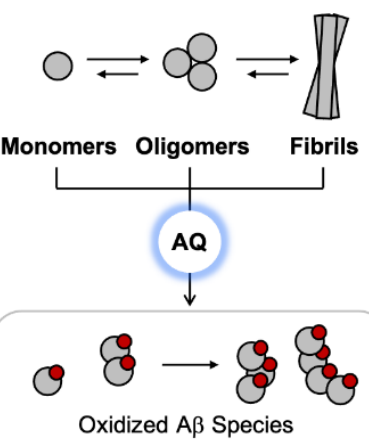

Off-pathway Aggregation

Induced by Peptide Oxidation

Figure 1. Rational selection of compact molecules that can modify the aggregation of $A \beta$ with photoactivation. (a) Chemical structures and properties of 9,10-AQ (Parent); HQ, Ali, Qui, Pur (Group A); Dan, Rhe, Alo (Group B). 9,10-AQ, 9,10-anthraquinone; HQ, 1hydroxyanthraquinone; Ali (alizarin), 1,2-dihydroxyanthraquinone; Qui (quinizarin), 1,4dihydroxyanthraquinone; Pur (purpurin), 1,2,4-trihydroxyanthraquinone; Dan (dantron), 1,8dihydroxyanthraquinone; Rhe (rhein), 4,5-dihydroxyanthraquinone-2-carboxylic acid; Alo (aloeemodin), 1,8-dihydroxy-3-(hydroxymethyl)-anthraquinone. (b) Sequence of A 3 . Hydrophobic residues are underlined. (c) Schematic description of the on-pathway aggregation of $A \beta$ with the modulatory strategy employing the photoactivated $\mathbf{A Q}$ series.

two groups: Group A (HQ, Ali, Qui, and Pur) possesses a hydroxyl group on the $\mathrm{R}_{1}$ position forming one quasi-ring with the adjacent ketone and additional hydroxyl groups on $\mathrm{R}_{2}$, $\mathrm{R}_{4}$, or both; Group B (Dan, Rhe, and Alo) contains hydroxyl groups on both $\mathrm{R}_{1}$ and $\mathrm{R}_{5}$ generating two quasirings and structural variance on $R_{3}$. The anthraquinone skeleton and the aforementioned structural variation can offer several advantages in targeting $A \beta$. The $A Q$ series has amphiphilic structures that can interact with $A \beta$ consisting of both hydrophilic and hydrophobic amino acid residues, as visualized in Figure 1b. The addition of hydroxyl and carbonyl groups with the ketone functionality can provide additional binding sites with $A \beta$ through hydrogen bonds. The anthracene $\pi$-plane backbone is not only essential for the photosensitizing ability but also enables hydrophobic interactions with the $\beta$-sheet in oligomeric and fibrillar $A \beta .{ }^{46}$ Hydroxyl groups and the 
neighboring ketone functionality are envisioned to serve as potential metal-binding sites that can interact with other metal ions bound to $A \beta$. Upon photoactivation, anthraquinones are reported to generate singlet oxygen $\left({ }^{1} \mathrm{O}_{2}\right)$, which are highly reactive towards diverse biological substrates. ${ }^{47,48}$ As such, we anticipated that $\mathbf{A Q}$ derivatives could readily oxidize amino acid residues in $A \beta$. We evaluated ${ }^{1} \mathrm{O}_{2}$ production of compact molecules in the $A Q$ series with mechanistic investigations and their reactivities towards both metal-free $A \beta$ and metal-A $\beta$, as depicted in Figure $1 \mathrm{c}$.

Mechanism for ${ }^{1} \mathrm{O}_{2}$ Generation. Density functional theory (DFT) calculations were performed to estimate the ability of our selected molecules to produce ${ }^{1} \mathrm{O}_{2}$ upon photoirradiation. As illustrated in Figure 2a, the energy transfer occurs from the triplet excited photosensitizer $\left({ }^{3} \mathbf{A Q}\right)$ to the acceptor triplet oxygen $\left({ }^{3} \mathrm{O}_{2}\right)$ resulting in a singlet ground state photosensitizer $\left({ }^{1} \mathbf{A Q}\right)$ and a singlet excited state acceptor $\left({ }^{1} \mathrm{O}_{2}\right) \cdot{ }^{49}$ Hydroxyanthraquinones exhibit excited-state intramolecular hydrogen transfer (ESIHT) from hydroxyl groups towards the adjacent ketone functionality during light activation. ${ }^{50}$ Moreover, hydroxyanthraquinones with deuterium substituted hydroxyl groups are reported to have longer emission lifetimes compared to the non-substituted analogues. ${ }^{51,52}$ Therefore, we can hypothesize that the energy transfer (i.e., donor relaxation) is directly linked to reverse intramolecular hydrogen transfer (RIHT). In support of this notion, the DFT-calculated barrier $\left(\Delta G^{\ddagger}\right)$ of the energy transfer for 9,10 -AQ to produce ${ }^{1} \mathrm{O}_{2}$ is unrealistically high at 138.9 $\mathrm{kcal} / \mathrm{mol}$ if intramolecular hydrogen transfer is not considered. The incorporation of the hydroxyl moiety enables intramolecular hydrogen transfer and reduces the triplet energy transfer barrier considerably, suggesting that hydroxyanthraquinones are suitable scaffolds for ${ }^{1} \mathrm{O}_{2}$ production. Specifically, calculations on Group A (HQ, Ali, Qui, and Pur; Figure 1a) that share a common backbone of 1-hydroxyl group next to the ketone functionality reveal low energy transfer barriers ranging from 1.3 up to $11.2 \mathrm{kcal} / \mathrm{mol}$. The molecules in Group B (Dan, Rhe, and Alo) with 1- and 8-hydroxyl moieties are predicted to be most efficient and barrierless.

We questioned why the position of hydroxyl groups has such a dramatic impact on the energy transfer barriers towards ${ }^{3} \mathrm{O}_{2}$ excitation. The triplet energy transfer barrier can be divided in two principal components: thermodynamic driving force $(\Delta G)$ and reorganization energy $(\lambda){ }^{53-}$ ${ }^{55} \Delta \mathrm{G}$ is the energy difference between the singlet-triplet energy gap of the donor and the acceptor. Comparing the frontier molecular orbitals of the donor scaffolds, all of our selected AQ derivatives bear delocalized singly occupied molecular orbital (SOMO) in their triplet state, as presented in Figure S1. The molecules in Group A present a smaller singlet-triplet energy gap of the donor where $\Delta G$ varies from -13.3 to $3.6 \mathrm{kcal} / \mathrm{mol}$. This small energy gap is due to the biased position of electron-donating groups and the resulting localized highest occupied molecular orbital 
(a)

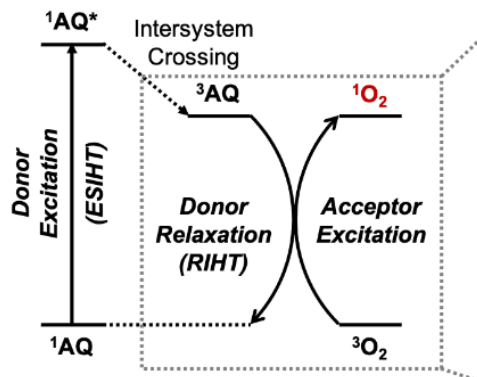

(b)

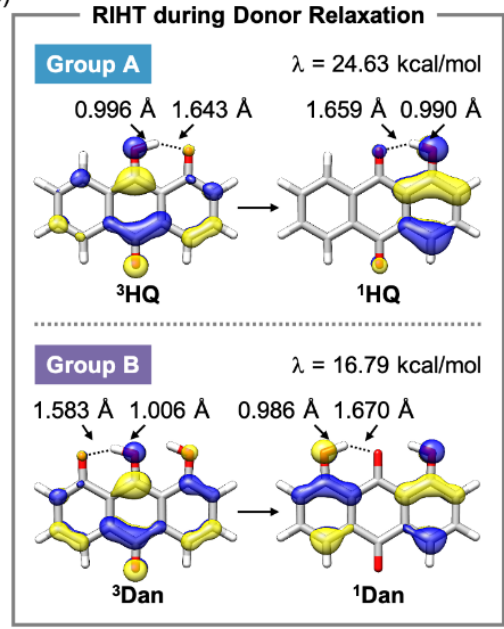

\begin{tabular}{|c|c|c|c|c|c|c|c|c|}
\hline & \multirow[b]{2}{*}{$\begin{array}{c}9,10- \\
\mathrm{AQ}\end{array}$} & \multirow{2}{*}{$\begin{array}{c}+{ }^{3} \mathrm{O}_{2} \\
\mathrm{HQ}\end{array}$} & \multicolumn{3}{|c|}{$\begin{array}{c}\Delta \mathrm{G}^{\ddagger}=\frac{(\Delta \mathrm{G}+\lambda)^{2}}{4 \lambda} \\
\begin{array}{c}\text { Energy Transfer } \\
(E T)\end{array}\end{array}$} & \multirow{2}{*}{$\begin{array}{l}{ }^{1} \mathbf{A Q} \\
\text { Dan }\end{array}$} & \multicolumn{2}{|c|}{$\begin{array}{l}+{ }^{1} \mathrm{O}_{2} \\
\quad \text { (Unit: kcal/mol) }\end{array}$} \\
\hline & & & Ali & Qui & Pur & & Rhe & Alo \\
\hline$\Delta \mathbf{G}$ & -37.90 & -13.30 & 3.57 & -5.80 & -0.13 & -16.10 & -14.67 & -16.21 \\
\hline$\lambda$ & 2.28 & 24.63 & 37.43 & 38.47 & 36.27 & 16.79 & 16.74 & 17.16 \\
\hline$\Delta \mathbf{G}^{\ddagger}$ & 138.91 & 1.30 & 11.23 & 6.93 & 9.00 & 0.01 & 0.06 & 0.01 \\
\hline
\end{tabular}

(c)

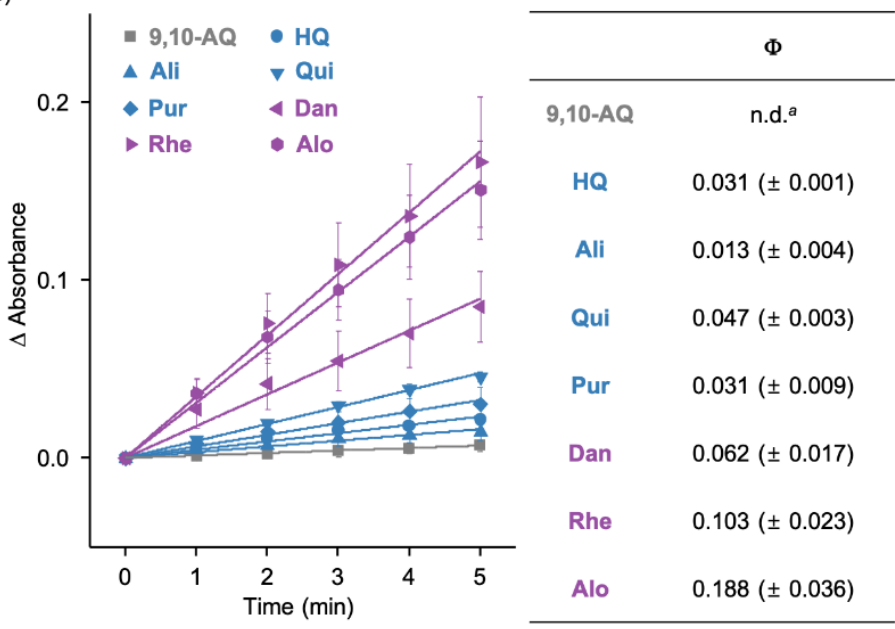

Figure 2. Production of ${ }^{1} \mathrm{O}_{2}$ by the $A Q$ series upon photoactivation. (a) DFT-calculated energy transfer barriers $\left(\Delta G^{\ddagger}\right)$ and their components $(\Delta G$, singlet-triplet free energy gap; $\lambda$, reorganization energy) for each compound. (b) Structural comparison between HQ (Group A) and Dan (Group B) and the key intramolecular hydrogen transfer that determines the different reorganization energy. (c) Amount of ${ }^{1} \mathrm{O}_{2}$ generated by the $A Q$ series with light exposure analyzed by the ABDA assay and their quantum yields $(\Phi)$. Error bars represent the standard error of the mean from three independent experiments. Conditions: [compound] $=25 \mu \mathrm{M}$; $[\mathrm{ABDA}]=100 \mu \mathrm{M}$; room temperature; Kessil lamp (467 nm) for 0, 1, 2, 3, 4, and 5 min. ${ }^{a}$ n.d., not determined due to the limited production of ${ }^{1} \mathrm{O}_{2}$.

(HOMO), which leads to a relatively unstable singlet ground state. The consequence is dramatic for the deprotonated Ali and Pur ( $\Delta \mathrm{G}$ of $3.6 \mathrm{kcal} / \mathrm{mol}$ and $-0.1 \mathrm{kcal} / \mathrm{mol}$, respectively) possessing phenolate moieties with a strong electron-donating character at neutral $\mathrm{pH}^{56}$ In contrast to Group A, the compounds in Group B retain symmetrically positioned hydroxyl groups with delocalized $\mathrm{HOMO}$ in the singlet ground state maintaining the singlet-triplet energy gap to a range of -16.2 to $-14.7 \mathrm{kcal} / \mathrm{mol}$. 
Another factor in determining the barrier is $\lambda$ associated with structural changes required for the energy transfer. Ranging from 24.6 to $38.4 \mathrm{kcal} / \mathrm{mol}$, the molecules in Group A generally require higher $\lambda$ values than those in Group $B$ that show $\lambda$ values of in the range of 16.7 to 17.1 $\mathrm{kcal} / \mathrm{mol}$. To better understand this trend, $\mathbf{H Q}(\lambda=24.6 \mathrm{kcal} / \mathrm{mol})$ and Dan $(\lambda=16.8 \mathrm{kcal} / \mathrm{mol})$ were chosen to represent molecules in Group A and Group B, respectively, as depicted in Figure 2b. The hydrogen bond in ${ }^{3} \mathrm{HQ}$ shortens from 1.64 to $1.00 \AA$ during donor relaxation, while the hydrogen bond involved in the hydrogen transfer in 3Dan displays a smaller change from 1.58 to $0.99 \AA$, indicating a reduced reorganization penalty compared to that of ${ }^{3} \mathrm{HQ}$. Two explanations can be offered to unveil the role of the additional hydroxyl group at the $\mathrm{R}_{1}$ position of Dan. In the context of intramolecular resonance-assisted hydrogen bonding, the extra hydroxyl functionality can serve as a m-electron-donating group to strengthen the hydrogen bond motif and, subsequently, shortens it. ${ }^{57}$ As another aspect, the additional hydrogen bond donor can withdraw the electron density from the interacting hydroxyl group and lower its $p K_{a}$ facilitating the hydrogen transfer process back to the singlet ground state structure. We reoptimized the triplet structure of ${ }^{3}$ Dan with the supplementary hydroxyl group to face the opposite direction and observed a slight elongation of the hydrogen bond length to $1.61 \AA$, which validates the dual effect of the hydroxyl group at $R_{1}$ in Group B, as described in Figure S2.

An alternative mechanism can be proposed for the excitation and relaxation of the photosensitizers during the triplet energy transfer: the stepwise procedure where the vertical relaxation of the triplet state comes first and RIHT comes later, as shown in Figure S3. Note that the mechanism of the concerted or stepwise pathway is still under debate because of the undetectable phosphorescence for hydroxyanthraquinones. Two types of vertical relaxation were examined through DFT and time-dependent density functional theory (TD-DFT) calculations: the $A Q$ series that (i) undergoes ESIHT in a stepwise manner or (ii) does not transfer their hydrogen upon excitation. In both of these cases, the reorganization energy is negligible and the singlettriplet energy gap is the only factor that determines the triplet energy transfer. According to our calculations, the ESIHT-assisted models exhibit an adequate energy gap to facilitate the triplet energy process. HQ, Ali, Qui, and Pur have an energy gap ranging from 10.8 to $22.0 \mathrm{kcal} / \mathrm{mol}$ that is insufficient for converting ${ }^{3} \mathrm{O}_{2}$ to ${ }^{1} \mathrm{O}_{2}$, while the energy gap of Dan, Rhe, and Alo ranges from 21.6 to $23.2 \mathrm{kcal} / \mathrm{mol}$ comparable to the energy of $22.5 \mathrm{kcal} / \mathrm{mol}$ needed to activate inert ${ }^{3} \mathrm{O}_{2}$. On the other hand, our hypothetical model that does not go through ESIHT and directly to intersystem crossing yields a larger singlet-triplet energy gap. HQ has an energy gap of 42.6 $\mathrm{kcal} / \mathrm{mol}$, but Ali and Pur present an energy gap between 12.4 and $18.9 \mathrm{kcal} / \mathrm{mol}$ that is too small. Dan, Rhe, and Alo have energy gaps in the range of 40.6 to $43.4 \mathrm{kcal} / \mathrm{mol}$, rendering them 
incompetent to achieve effective triplet energy transfer to the oxygen acceptor. Therefore, ESIHT plays a significant role for the $\mathbf{A Q}$ series not only in the concerted but also in the stepwise mechanism to become appropriate photosensitizers by controlling the singlet-triplet energy gap. Taken together, our computational studies highlight the importance of additional hydroxyl groups and reveal that the position of hydrogen bond donors are key to facilitate the triplet energy transfer.

${ }^{1} \mathrm{O}_{2}$ Production. Photochemical properties of the $A Q$ series used in this study were examined by ultraviolet-visible (UV-Vis) and fluorescence spectroscopies. As summarized in Figure S4, the absorption spectra of the AQ series in dimethyl sulfoxide (DMSO) or the buffered solution showed maxima in the range of 326-486 and 335-516 nm, respectively, denoting photon absorbance in the blue light region. Especially, the absorption of Ali and Pur in the buffered solution displayed bathochromic shifts ( $\lambda=82$ and $21 \mathrm{~nm}$, respectively), relative to maximum in DMSO, because the hydroxyl group at the $\mathrm{R}_{2}$ position is deprotonated at neutral $\mathrm{pH}^{56}$ Moreover, the luminescence spectra of the $\mathbf{A Q}$ series in DMSO and the buffered solution were measured, as presented in Figure S5. While 9,10-AQ had a maximum emission wavelength at $425 \mathrm{~nm}$ in DMSO and diminished absorbance in the buffered solution, the rest of the $A \mathbf{Q}$ series emitted light within the range of 554-612 nm upon illumination. Luminescence of Ali and Pur was not observed in the buffered solution.

The capability of the AQ series to produce 102 in the wavelength of the blue light spectrum (ca. $467 \mathrm{~nm}$ ) was evaluated employing the ABDA assay [ABDA $=9,10$-Anthracenediylbis(methylene)-dimalonic acid]. As illustrated in Figures $2 \mathrm{c}$ and $\mathrm{S} 6$, the absorbance attenuation $(\triangle \mathrm{A})$ of $\mathrm{ABDA}$ in the presence of the $\mathbf{A Q}$ series under aerobic conditions revealed the energy transfer from the compounds in Group $B$ towards $\mathrm{O}_{2}$ exhibiting a range of $\Phi$ from 0.062 up to 0.188 comparable to $\left[\mathrm{Ru}(\mathrm{bpy})_{3}\right]^{2+}\left(\Phi=0.18 \text { in } \mathrm{H}_{2} \mathrm{O}\right)^{58-60}$ as a reference molecule. The molecules in Group A displayed moderate or low ${ }^{1} \mathrm{O}_{2}$ formation with a $\Phi$ range from 0.013 to 0.047 . Note that the $\Phi$ value of $\mathbf{9 , 1 0 - A Q}$ could not be obtained due to the minimum changes of the absorption peaks of ABDA. Therefore, the photochemical measurements confirm that the AQ series generates ${ }^{1} \mathrm{O}_{2}$ and the molecules in Group B are most effective. These results are in line with the computational estimates of the triplet energy transfer barrier.

$A \beta$ Oxidation. To determine whether the $A Q$ series can oxidatively modify metal-free and metal$A \beta$ with photoirradiation under aerobic conditions, the resultant $A \beta$ species were analyzed by electrospray ionization-mass spectrometry (ESI-MS) and tandem MS (ESI-MS ${ }^{2}$ ). As displayed in Figure 3, no significant change in metal-free $A \beta_{40}$ was observed in the absence of light. Upon 

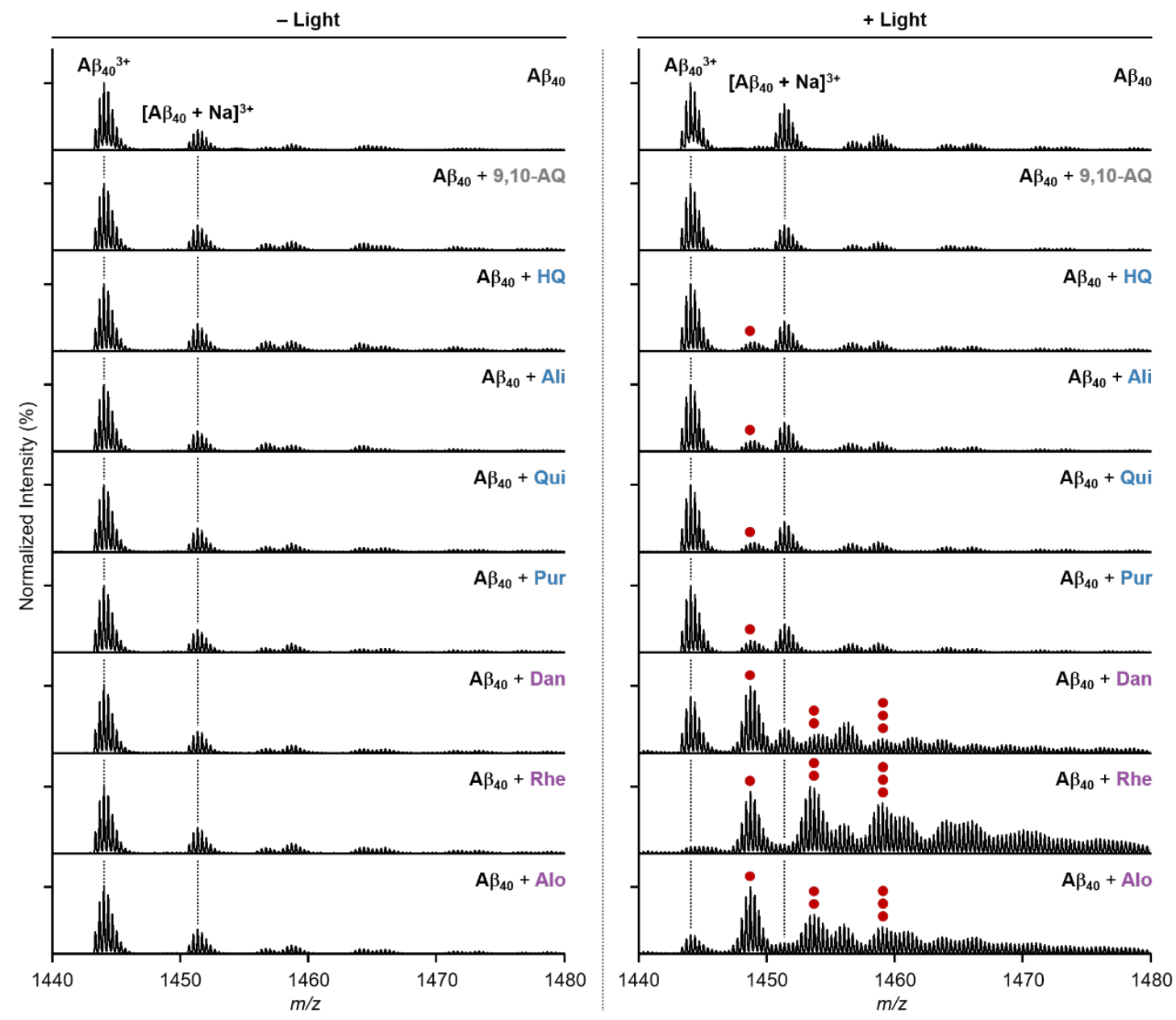

Figure 3. Analysis of $A \beta_{40}$ species produced by treatment of the $A Q$ series with and without light exposure by ESI-MS. The number of red dots represents the number of oxygen atoms incorporated into $A \beta_{40}$ monomer $\left[A \beta_{40}+n O\right]^{3+}(n=1,2$, or 3$)$. Conditions: $\left[A \beta_{40}\right]=25 \mu M$; [compound] $=50 \mu \mathrm{M} ; 20 \mathrm{mM}$ ammonium acetate (1\% v/v DMSO), $\mathrm{pH} 7.4 ; 37^{\circ} \mathrm{C} ; 3 \mathrm{~h}$; constant agitation (250 rpm); Kessil lamp $(467 \mathrm{~nm})$ for $1 \mathrm{~h}$. The samples were diluted by 5 -fold with $\mathrm{H}_{2} \mathrm{O}$ before injection to the mass spectrometer.

photoactivation of the $\mathbf{A Q}$ series, the peaks corresponding to oxidized $A \beta_{40}$ species were monitored. The parent molecule 9,10-AQ did not affect $A \beta_{40}$ despite light exposure. When $\mathbf{H Q}$, Ali, Qui, and Pur (Group A) were exposed to $A \beta_{40}$, a new peak was detected at 1,448 $\mathrm{m} / \mathrm{z}$, indicative of the incorporation of a single oxygen atom into monomeric $A \beta_{40}$. In the case of Dan, Rhe, and Alo (Group B), three new peaks were detected at 1,448, 1,453, and 1,459 $\mathrm{m} / \mathrm{z}$ corresponding to the singly, doubly, and triply oxidized $A \beta_{40}$ monomers, respectively. The singly, 

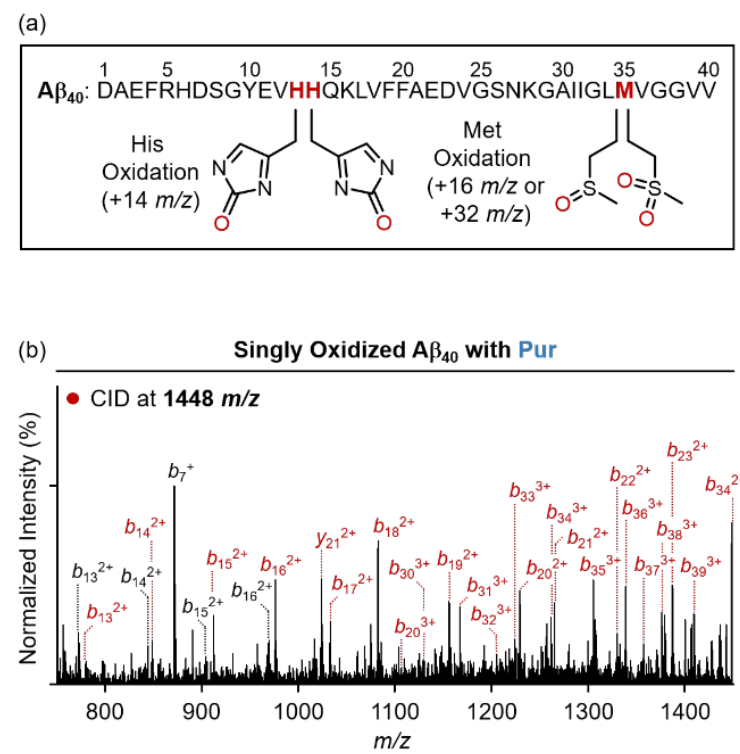

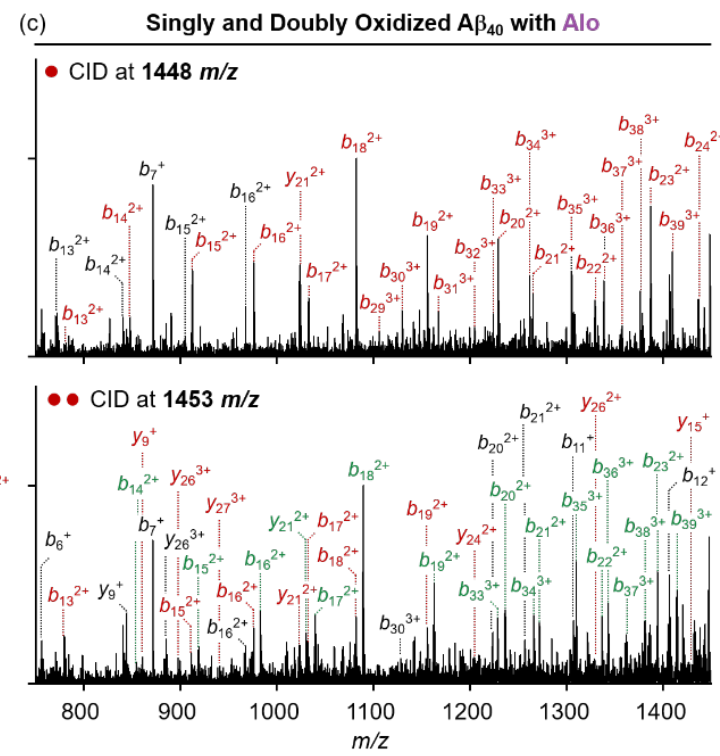

Figure 4. Identification of the oxidized amino acid residues in $A \beta_{40}$ by the photoactivated $\mathbf{A Q}$ series through ESI-MS ${ }^{2}$. (a) Sequence of $A \beta_{40}$ and structures of oxidized His and Met residues. ( $b$ and c) ESI-MS ${ }^{2}$ analyses of the singly oxidized peak $(m / z=1448$; Figure 3 ) obtained by treatment of Pur as well as the singly and doubly oxidized peaks ( $\mathrm{m} / \mathrm{z}=1448$ and 1453, respectively; Figure 3) generated upon incubation with Alo. In the ESI-MS ${ }^{2}$ studies, monooxidized and dioxidized $b$ and $y$ ions are illustrated in red and green, respectively. Conditions: $\left[A \beta_{40}\right]=25 \mu \mathrm{M}$; [compound $]=50 \mu \mathrm{M} ; 20 \mathrm{mM}$ ammonium acetate (1\% v/v DMSO), $\mathrm{pH} 7.4 ; 37^{\circ} \mathrm{C}$; $3 \mathrm{~h}$; constant agitation (250 rpm); Kessil lamp (467 nm) for $1 \mathrm{~h}$. The samples were diluted by 5fold with $\mathrm{H}_{2} \mathrm{O}$ before injection to the mass spectrometer.

doubly, or triply oxidized $A \beta_{40}$ monomer induced by the light-activated $\mathbf{A Q}$ series was also noticed in both $\mathrm{Zn}(\mathrm{II})-\mathrm{A} \beta_{40}$ and $\mathrm{Cu}(\mathrm{II})-\mathrm{A} \beta_{40}$, as shown in Figure $\mathrm{S7}$.

The peaks assigned to oxidized $A \beta_{40}$ species generated by photoactivation were further probed by ESI-MS ${ }^{2}$ to identify the oxidized amino acid residues (Figure $4 a$ ). $A \beta_{40}$ peptides photooxygenated with Pur (Group A) and Alo (Group B) to different extents were selected for tandem MS measurements. Figure $4 \mathrm{~b}$ exemplifies the collision-induced dissociation (CID) experiments on the singly oxidized peak of $A \beta_{40}(1,448 \mathrm{~m} / \mathrm{z})$ obtained by photoexcited Pur. We observed $b$ fragments smaller than $b_{35}$ and larger than $b_{12}$ in their nonoxidized and oxidized forms, respectively. The $b$ fragments between $b_{13}$ and $b_{34}$ were found in both nonoxidized and oxidized forms. These observations imply that Pur oxidizes either His13, His14, or Met35 separately, but it is unable to simultaneously modify more than one residue. On the contrary, as disclosed in 
Figure 4c, ESI-MS ${ }^{2}$ studies on the singly and doubly oxidized peaks verified that Alo can concurrently oxidize all three aforementioned amino acid residues. The fragmentation analysis on the singly oxidized $A \beta_{40}$ by Alo was identical with the results obtained by Pur. For the doubly oxidized $A \beta_{40}$, we could not monitor oxidized fragments smaller than $b_{13}$, and doubly oxidized forms were detected from $b$ ions larger than $b_{13}$. Note that the Met residue was oxidized up to sulfone in the doubly oxidized $A \beta_{40}$. Overall, our MS studies substantiate that the $A Q$ series can oxidize $A \beta$ possibly at the His13, His14, and Met35 residues to varying degrees.

Influence on $\mathbf{A} \boldsymbol{\beta}$ Aggregation. To test if the different degree of $A \beta$ oxidation by light activation of the molecules in Group A and Group B alters the aggregation of both metal-free $A \beta$ and metal$A \beta$ in a detectable manner, the molecular weight (MW) distribution of the resultant $A \beta$ species was first analyzed by gel electrophoresis with Western blotting (gel/Western blot) using an anti$A \beta$ antibody (6E10). The morphological change of metal-free $A \beta$ or metal-A $\beta$ aggregates produced by treatment of the $A Q$ series was visualized with transmission electron microscopy (TEM). A $\beta$ aggregates larger than ca. $270 \mathrm{kDa}$ are not detectable in gel/Western blot but can be probed by TEM. In this work, we conducted two experiments: (i) inhibition experiments for determining the influence of the $A Q$ series on the formation of $A \beta$ aggregates; (ii) disaggregation experiments for assessing the ability of the $A Q$ series to disassemble pre-formed $A \beta$ aggregates. In the inhibition experiments, metal-free or metal-A $\beta$ was freshly prepared and treated for $24 \mathrm{~h}$ with the $\mathbf{A Q}$ series, as shown in Figure 5a. For light-exposed samples, $A \beta$ species added with the $A Q$ series were photoirradiated for $1 \mathrm{~h}$ prior to $24 \mathrm{~h}$ incubation. As portrayed in Figure $5 \mathrm{~b}$, under dark conditions (grey gels), no significant change in the MW distribution of both metal-free and metal-A $\beta_{40}$ was observed even with the addition of the $A Q$ series. Notably, in the presence of light, the resultant $A \beta_{40}$ species with the $A Q$ series (blue gels) showed a divergent $M W$ distribution, relative to $A \beta_{40}$ only. Treatment of metal-free $A \beta_{40}$ with light-activated 9,10-AQ, HQ, Ali, Qui, and Pur gave rise to increased signal intensities between ca. 15-35 kDa. Note that the $A Q$ series can produce superoxide anion radicals; ${ }^{61}$ however, we could not monitor them because the excitation and emission wavelengths used for the assays overlapped with those of the compounds. On the contrary, the illuminated $A \beta_{40}$ samples with Dan, Rhe, and Alo greatly affected the MW distribution exhibiting new gel bands throughout ca. 15-240 kDa. Smearing bands over ca. $240 \mathrm{kDa}$ were spotted for the samples added with both Group A and Group B indicating that the light-driven oxidation of metal-free $A \beta_{40}$ leads to smaller peptide ensembles that can penetrate the gel matrix. In the inhibition experiments with $\mathrm{Zn}(\mathrm{II})-\mathrm{A} \beta_{40}, \mathbf{9 , 1 0 - A Q}, \mathbf{H Q}, \mathbf{A l i}, \mathbf{Q u i}$, and Pur upon 


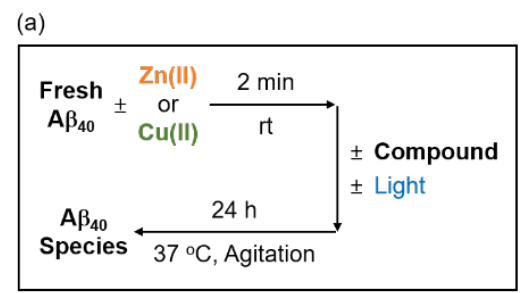

(b)
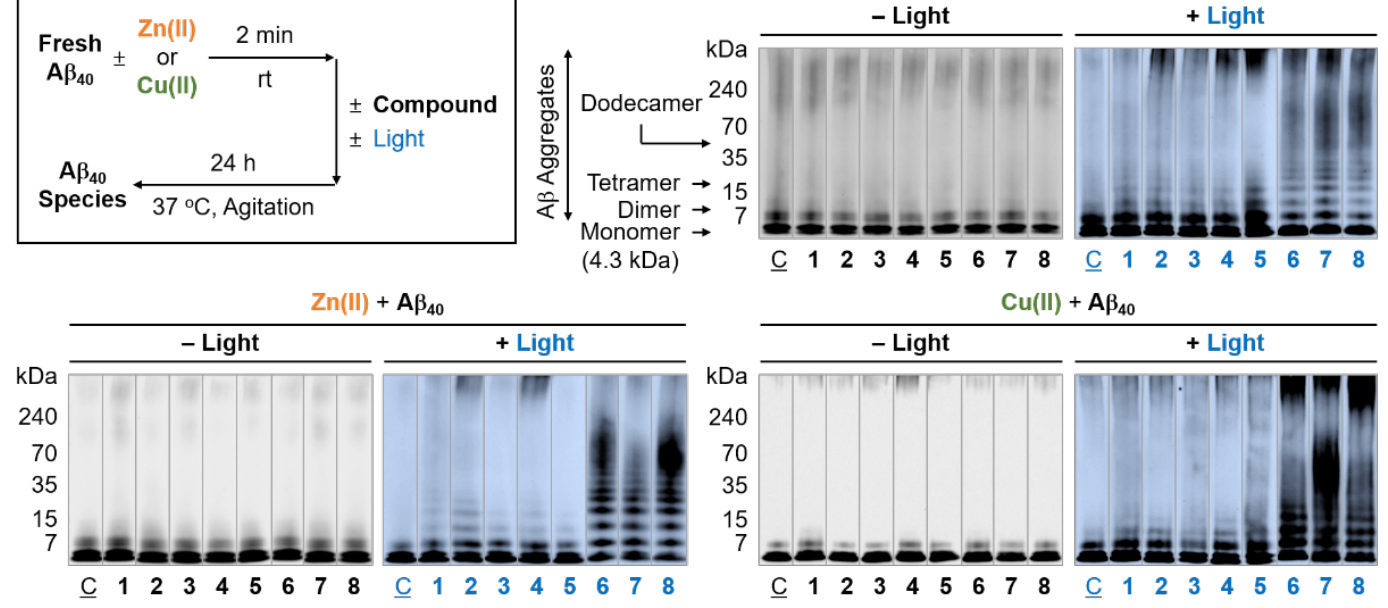

(c)
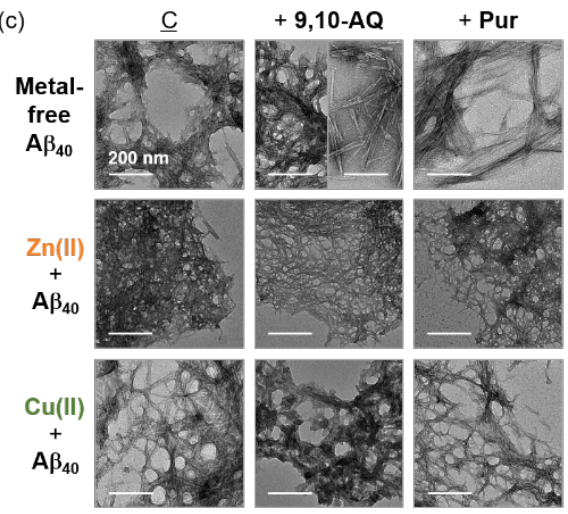

+ Alo
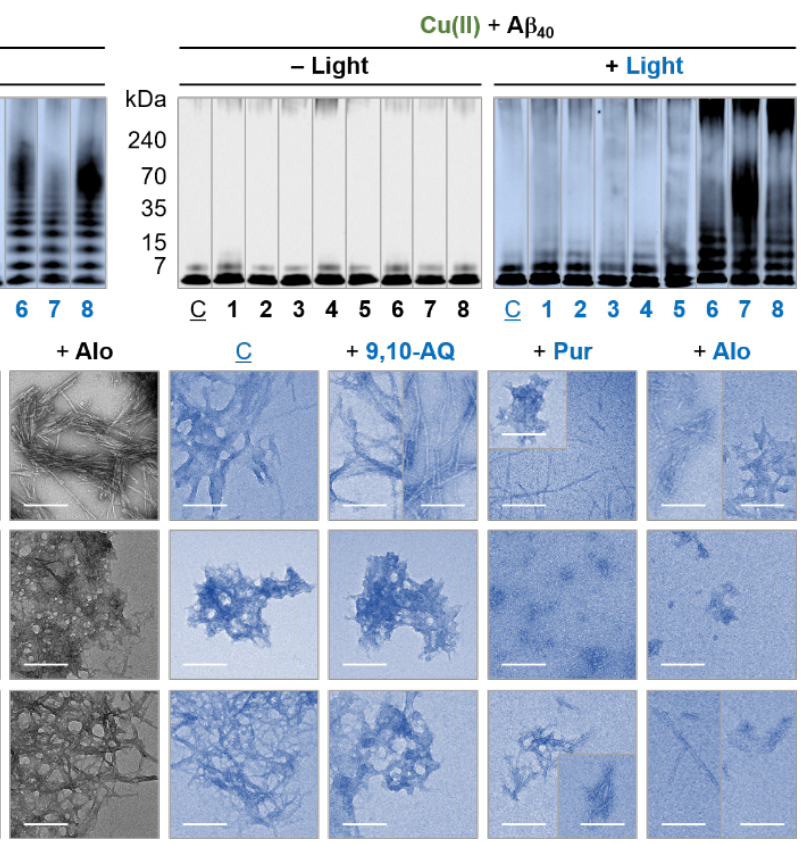

C

$+9,10-A Q$

+ Pur

+ Alo
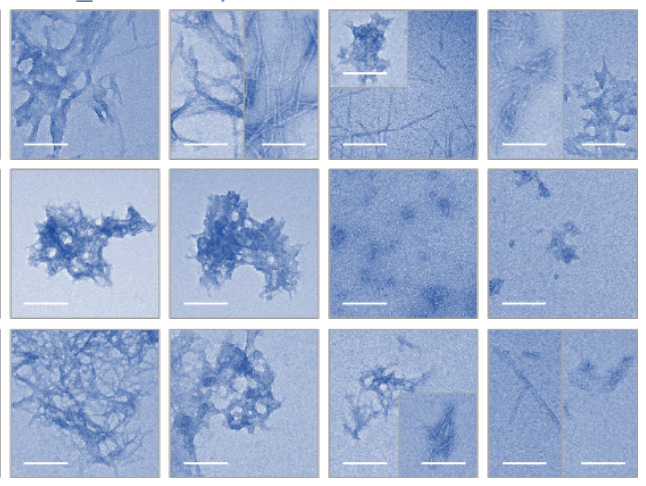

Figure 5. Impact of the $A Q$ series on the formation of metal-free or metal-treated $A \beta_{40}$ aggregates with and without light activation. (a) Scheme of the inhibition experiments. (b) Gel/Western blots (anti-A $\beta$ antibody, $6 E 10$ ) of the resultant $A \beta_{40}$ species upon incubation of metal-free and metaladded $A \beta_{40}$ with and without treatment of compounds and light. Lanes: (므) $A \beta_{40}$; (1) $A \beta_{40}+\mathbf{9 , 1 0 -}$ $A Q$; (2) $A \beta_{40}+H Q$; (3) $A \beta_{40}+$ Ali; (4) $A \beta_{40}+$ Qui; (5) $A \beta_{40}+$ Pur; (6) $A \beta_{40}+$ Dan; (7) $A \beta_{40}+$ Rhe; (8) $A \beta_{40}+$ Alo. (c) TEM images of the aggregates produced upon $24 \mathrm{~h}$ incubation of metal-free and metal-treated $A \beta_{40}$ with and without the $A Q$ series in the absence and presence of light. Conditions: $\left[A \beta_{40}\right]=25 \mu \mathrm{M} ;[\mathrm{M}(\mathrm{II})]=25 \mu \mathrm{M}$; [compound $]=50 \mu \mathrm{M} ; 20 \mathrm{mM}$ HEPES (1\% v/v DMSO), $\mathrm{pH} 7.4$ [for metal-free or $\mathrm{Zn}(\mathrm{II})$-containing samples] or $\mathrm{pH} 6.6$ [for $\mathrm{Cu}(\mathrm{II})$-added samples], $150 \mathrm{mM}$ $\mathrm{NaCl} ; 37^{\circ} \mathrm{C}$; $24 \mathrm{~h}$; constant agitation (250 rpm); Kessil lamp (467 nm) for $1 \mathrm{~h}$. Scale bar $=200$ $\mathrm{nm}$.

photoactivation mildly affected the MW distribution while Dan, Rhe, and Alo significantly enhanced the intensities of the bands between ca. 15-240 kDa. Various aggregates were 
detected upon incubation of $\mathrm{Cu}(\mathrm{II})-\mathrm{A} \beta_{40}$ with photoreactive Dan, Rhe, and Alo, but moderate effects were identified with the illumination of the rest of the $A Q$ series.

As described in Figure $5 c$, metal-free $A \beta_{40}$ and metal-A $\beta_{40}$ aggregates generated with and without the treatment of 9,10-AQ, Pur, or Alo were further examined by TEM. 9,10-AQ, Pur, and Alo were chosen as the representative molecules of Parent, Group A, and Group B, respectively. Without light, morphologies of the resultant metal-A $\beta_{40}$ aggregates were not significantly changed even with the compounds. Thick fibrils were formed by incubation of metal-free $A \beta_{40}$ in the presence of all three compounds, compared to fibrillary aggregates produced in the sample of metal-free $A \beta_{40}$ only. This suggests that the $A Q$ backbone itself may interact with metal-free $A \beta_{40}$ and affect its aggregation. When 9,10-AQ was incubated with metal-free $A \beta_{40}$ with photoirradiation, long and thick fibrils as well as similar fibrils to those formed from $A \beta_{40}$ only were detected. The conformational transformation of metal-free $A \beta_{40}$ by photoexcited Pur and Alo was more noticeable than that by $9,10-A Q$ resulting in smaller and thinner aggregates. In the case of metal$A \beta_{40}$ species, small amorphous assemblies and thin fibrils were visualized with the illumination of Pur and Alo, but 9,10-AQ did not noticeably alter their morphologies. These amorphous aggregates are reported to be less toxic than structured assemblies. ${ }^{15,17,19}$ Modest or no changes found in the structures of metal-free and metal-bound $A \beta_{40}$ species with photoactivated $\mathbf{9 , 1 0 - A Q}$ denote the importance of efficient ${ }^{1} \mathrm{O}_{2}$ production in modifying their aggregation pathways.

Inhibition experiments were also conducted employing $A \beta_{42}$, as presented in Figure $S 8$. The application of light with 9,10-AQ towards metal-free $A \beta_{42}$ enhanced the band intensity in the high MWs (ca. over $70 \mathrm{kDa}$ ). $\mathrm{HQ}$ and Ali did not significantly change MW distribution with photoirradiation. The addition of light-exposed Qui, Pur, and Dan reduced the intensities of the bands in the lower MW region (ca. below $15 \mathrm{kDa}$ ) but increased them in the higher MW region (ca. over $70 \mathrm{kDa}$ ). This phenomenon was distinct from the samples of Rhe and Alo with light. In the presence of $\mathrm{Zn}(\mathrm{II})$, smearing bands emerged in the case of Pur, Dan, Rhe, and Alo throughout ca. 4-270 kDa. In Ali- and Qui-added samples, a new band at ca. $7 \mathrm{kDa}$ and amplified the intensities of bands over ca. $35 \mathrm{kDa}$ were monitored. Such change of the band above ca. 70 kDa was also observed upon treatment of 9,10-AQ and $\mathbf{H Q}$. The $\mathrm{Cu}(\mathrm{II})$-added samples with the photoilluminated $\mathbf{A Q}$ series presented the changes in the MW distribution to different extents. Similar to $A \beta_{40}$, TEM studies showed that 9,10-AQ, Pur, and Alo did not noticeably alter the morphologies of metal-free and metal-A $\beta_{42}$ aggregates without light. The size of metal-free $A \beta_{42}$ and metal-A $\beta_{42}$ aggregates was greatly diminished by photoexcited Alo, and thinner fibrils and smaller aggregates were spotted by addition of Pur, compared to compound-free metal-free and metal-A $\beta_{42}$ aggregates. 
Moving forwards, as depicted in Figure S9, metal-free or metal-A $\beta$ was pre-incubated for $24 \mathrm{~h}$ to form peptide aggregates and the $A Q$ series was treated with and without $1 \mathrm{~h}$ photoexcitation followed by incubation for an additional $24 \mathrm{~h}$. The gel/Western blots in the disaggregation experiments afforded shifts in the MW distribution of $A \beta$ species to various degrees upon photosensitization of the $A Q$ series. Specifically, the MW distribution of pre-formed metal-free $A \beta_{40}$ aggregates was influenced by 9,10-AQ, HQ, Ali, Qui, Pur, Dan, and Rhe exhibiting new bands between ca. 15-35 kDa. Light-exposed Ali, Qui, Pur, Dan, Rhe, and Alo showed dimmer or no bands in the MW region below ca. $7 \mathrm{kDa}$. Substantial MW changes of $\mathrm{Zn}(\mathrm{II})-\mathrm{A} \beta_{40}$ aggregates incubated with Dan, Rhe, and Alo were observed with new bands throughout ca. 15-270 kDa. In the case of Qui and Pur, the intensities at ca. $7 \mathrm{kDa}$ and above $240 \mathrm{kDa}$ were increased, but photoactivated 9,10-AQ, HQ, and Ali manifested less pronounced impact on the MW distribution. The gel/Western blot of pre-formed $\mathrm{Cu}(\mathrm{II})-\mathrm{A} \beta_{40}$ aggregates also indicated an amplified variation in the MW distribution with Dan, Rhe, and Alo while the treatment of 9,10-AQ and the molecules in Group $A$ resulted in minor or no changes. For metal-free $A \beta_{42}$ aggregates, we were not able to detect a significant MW change with 9,10-AQ, but slight alterations were found with $\mathbf{H Q}$ and Ali. The addition of Qui and Pur displayed lower band intensities below ca. $15 \mathrm{kDa}$. On the other hand, the intensities of the bands throughout the detectable region observed in the sample of $A \beta_{42}$ only were all diminished in the presence of Dan, Rhe, and Alo. Likewise, the MW distribution of metal-A $\beta_{42}$ aggregates with photoactivated 9,10$A Q$ was negligibly varied. Against $Z n(I I)-A \beta_{42}$ aggregates, the illumination of Group $A$ and Group B increased the intensity in the higher-order region above ca. $35 \mathrm{kDa}$. Furthermore, $\mathbf{H Q}$ and Qui produced a new band at ca. $7 \mathrm{kDa}$ with smearing near ca. $15 \mathrm{kDa}$. Pur, Dan, Rhe, and Alo decreased the intensity below ca. $15 \mathrm{kDa}$. A change in the MW distribution of $\mathrm{Cu}(\mathrm{II})-\mathrm{A} \beta_{42}$ aggregates was also monitored by treatment of Group A and Group B in different ranges. Photoactivated $\mathbf{H Q}$ lowered the intensity between ca. 7-35 kDa, where the bands in the corresponding region became more obscure for Ali, Qui, and Pur. Dan resulted in the smearing throughout ca. 7-240 kDa while the bands almost disappeared in the region below ca. $70 \mathrm{kDa}$ for $\mathrm{Cu}(\mathrm{II})-\mathrm{A} \beta_{42}$ aggregates added with $\mathbf{R h e}$ and $\mathbf{A l o}$.

Taken together, the gel/Western blot and TEM studies implicitly demonstrate the ability of photoexcited $A Q$ series for modulating the formation of metal-free $A \beta$ or metal-A $\beta$ aggregates as well as the disassembly of pre-formed metal-free or metal-added $A \beta$ aggregates. The impact of photoreactive $A Q$ series against diverse $A \beta$ species reflects the significance of ${ }^{1} \mathrm{O}_{2}$ production and the number of oxygen atoms incorporated into $A \beta$; thus, the compounds in Group $B$ are able to remarkably modify the aggregation pathways of both metal-free $A \beta$ and metal-A $\beta$. Furthermore, 
taking account to minimum changes noticed in the parent structure $\mathbf{9 , 1 0 - A Q}$, these in vitro aggregation investigations reveal the relationship between the structural features (e.g., the position and number of hydroxyl groups placed in the framework) of the $A Q$ series and the modulatory reactivity towards the aggregation of metal-free $A \beta$ and metal-A $\beta$.

Biological Efficacies. The cell viability and BBB permeability of the AQ series were examined prior to in vivo studies. Photodegradation of photosensitizers during illumination was reported to yield unidentified fragments that can cause toxicity. ${ }^{62}$ Thus, the toxicity of the compounds prepared with and without photoirradiation was determined in human neuroblastoma SH-SY5Y (5Y) cells by the MTT assay [MTT = 3-(4,5-dimethylthiazol-2-yl)-2,5-diphenyltetrazolium bromide]. As described in Figure S10, the cells in the presence of both Group A and Group B without photoactivation exhibited greater survival of over ca. $80 \%$ at up to $25 \mu \mathrm{M}$. The parent moiety $\mathbf{9 , 1 0 -}$ AQ displayed over $70 \%$ cell viability. Intriguingly, the toxicity of all molecules pre-illuminated for 1 $\mathrm{h}$ before $24 \mathrm{~h}$ incubation was lowered by up to ca. $14 \%$ at $25 \mu \mathrm{M}$. This suggests that the $\mathbf{A Q}$ series does not yield more toxic products upon photoactivation.

Crossing the BBB is an essential factor for chemical reagents to be utilized in the brain. ${ }^{63}$ Thus, the brain uptake of the $\mathbf{A Q}$ series was predicted by the parallel artificial membrane permeability assay adapted for the BBB.64,65 As summarized in Table S1, most of the molecules selected in this study were expected to have sufficient BBB penetration with a $-\log P_{\mathrm{e}}$ value below 5.4 except for Rhe $\left[-\log P_{\mathrm{e}}\right.$ of $\left.5.97( \pm 0.03)\right]$. The permeability of $\mathbf{9 , 1 0}$-AQ could not be determined due to limited solubility in water. Moving forward, we chose to examine Alo in histochemical investigations in vivo because it showed a relatively high ${ }^{1} \mathrm{O}_{2}$ quantum yield in the $A Q$ series, significant modulatory impact on $A \beta$ aggregation, relatively low cytotoxicity, and potential $B B B$ permeability.

To assess the aggregation propensity of $A \beta_{42}$ species treated with Alo and light in the brain, we conducted histochemical studies on the brain samples injected with Alo-treated $A \beta_{42}$ species. As illustrated in Figure 6a, $A \beta_{42}$ was freshly prepared in $20 \mathrm{mM} \mathrm{HEPES,} \mathrm{pH} \mathrm{7.4,} 150 \mathrm{mM} \mathrm{NaCl}$ ( $1 \% \mathrm{v} / \mathrm{v}$ DMSO; vehicle), exposed to light for $1 \mathrm{~h}$ with and without Alo, incubated for an additional $2 \mathrm{~h}$, and directly injected into the hippocampus of murine brains. The hippocampal region is vital for memory formation and retrieval in both murine and human brains and is highly affected by $A \beta$ aggregates formed during the progression of $A D .{ }^{66-68}$ After 15 days of injection, the brain sections were obtained and stained with antibodies or fluorescence dyes to determine the deposition of $A \beta$ oligomers or fibrils in the hippocampus. As displayed in Figure 6b, both 


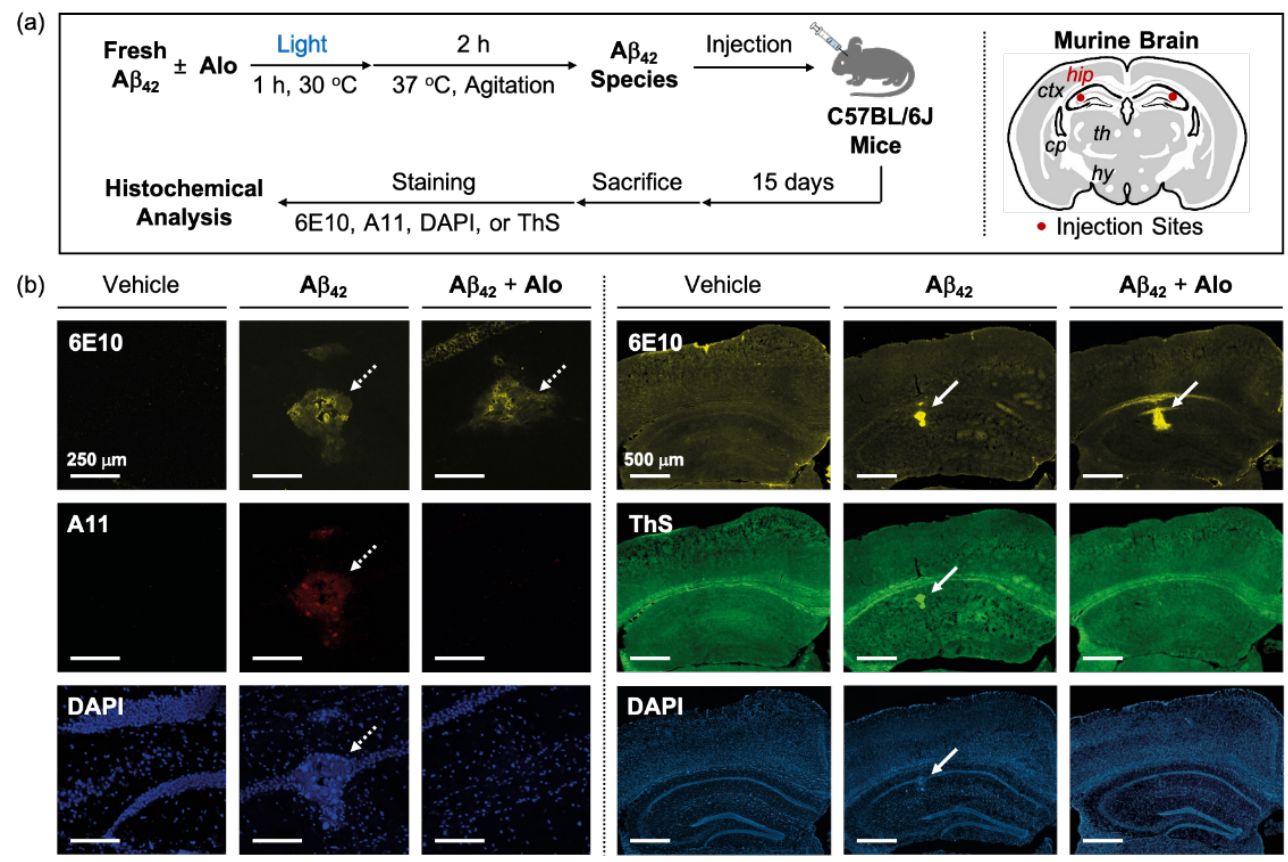

Figure 6. Detection of $A \beta_{42}$ aggregate deposition in murine brains injected with photoactivated Alo-treated $A \beta_{42}$ species. (a) Schematic description of histochemical studies and injection sites in the brain. Hippocampus (hip), cortex (ctx), thalamus (th), caudate putamen (cp), and hypothalamus (hy) are shown. (b) Microscopic images of the hippocampi of C57BL/6J mice injected with vehicle, $A \beta_{42}$, or Alo-treated $A \beta_{42}$. $A \beta$ species were prepared in $20 \mathrm{mM} \mathrm{HEPES}, \mathrm{pH}$ $7.4,150 \mathrm{mM} \mathrm{NaCl}$ (1\% v/v DMSO; vehicle) and visualized by immunostaining [primary antibodies, 6E10 (anti-A $\beta$ antibody; yellow) and A11 (anti-oligomer antibody; red), with fluorescentconjugated secondary antibodies] or fluorescent dyes (ThS for A $\beta$ fibrils; green), and DAPI (for fibrillary $A \beta$ and nucleus; blue). Images were taken by a confocal microscope (left; $x 10)$ or a scanning microscope (right; x10). Detected amyloid species are marked with white arrows. Scale bars $=250 \mu \mathrm{M}$ and $500 \mu \mathrm{M}$ for confocal or scanning microscopies, respectively. Animal numbers; $n=4$ (for $A \beta_{42}$ and Alo-added $A \beta_{42}$ ) and $n=2$ (for vehicle).

compound-free and Alo-added $A \beta_{42}$ species were safely injected into the hippocampal region, as confirmed by immunostaining with an anti-A $\beta$ primary antibody (6E10). ${ }^{69,70}$ Interestingly, only the brain samples, which were administered with compound-free $A \beta_{42}$ species and incubated for a long time in vivo, showed the formation of $A \beta_{42}$ aggregates such as oligomers [detected by immunostaining with an anti-oligomer primary antibody $(A 11)^{71}$ ] or fibrils \{visualized with fluorescent dyes [thioflavin-S (ThS) for $A \beta$ fibrils ${ }^{72,73}$ or DAPI for $A \beta$ fibrils and cellular nuclei ${ }^{74,75}$ ]\}. 
Oligomeric and fibrillar aggregates were not significantly visible in the brain samples injected with $A \beta_{42}$ species oxidized by photoactivated Alo. Given that $A \beta_{42}$ oligomers are reported to be neurotoxic by various pathways (e.g., interacting with cellular membranes and damaging intracellular organelles) $)^{13,76,77}$ and fibrillary amyloid plaques are another pathologic feature upon the progression of $A D,{ }^{78,79}$ these overall results imply that the less toxic, off-pathway assembly of the resultant oxidized $A \beta$ species by Alo with photoactivation takes place in vivo

\section{CONCLUSIONS}

Regulating the aggregation of $A \beta$ peptides via diverse approaches such as chemical transformations has been a long-lasting interest and challenge to alleviate the progression of $A D .^{13}$ There has been controversy of the specific role of $A \beta$ in $A D$, but recent reports continue to emphasize the necessity of our study. ${ }^{80}$ The demand of finding an appropriate reagent for PDT oxidatively modifying pathological factors in $A D$ requires both effective ${ }^{1} \mathrm{O}_{2}$ production and nontoxic byproducts. Our structure-based computational modeling of small AQ-based molecules highlights the importance of the adequate level of the singlet-triplet energy gap associated with the reorganization energy throughout the ESIHT process. These conditions were met by incorporating additional hydroxyl groups to form two quasi-ring moieties that facilitate ${ }^{1} \mathrm{O}_{2}$ production. Spectroscopic and biochemical studies demonstrate the enhanced photoreactivity of the $A Q$-based reagents with two quasi-rings mediated by hydrogen bonding against metal-free $A \beta$ and metal-A $\beta$, compared to the molecules that possess one or no intramolecular quasi-ring. The $\mathbf{A Q}$ series also displayed relatively lower cellular toxicity upon photoactivation. Moreover, in the brains of mice, $A \beta$ species generated by Alo with light exposure exhibited minimum aggregation into amyloid assemblies such as oligomers or fibrils known to be linked to the pathology of $A D$. Overall, our combined experimental and computational studies illuminate that the mechanism-based tuning of the intramolecular hydrogen bonds in photosensitizers exhibiting ESIHT leads to prolific outcomes in controlling pathological factors in AD and can contribute towards rationally designing effective chemical reagents for gaining a better understanding of the pathology of the disease.

\section{AUTHOR INFORMATION}

\section{Corresponding Author}

*miheelim@kaist.ac.kr

*mbaik2805@kaist.ac.kr

*shlee1@kaist.ac.kr 


\section{ORCID}

Mi Hee Lim: 0000-0003-3377-4996

Mu-Hyun Baik: 0000-0002-8832-8187

Seung-Hee Lee: 0000-0002-9486-5771

Mannkyu Hong: 0000-0002-7770-1230

\section{Author Contributions}

$\|$ M.H. and M.K. contributed equally to this work.

\section{Notes}

The authors declare no competing financial interests.

\section{ACKNOWLEDGEMENTS}

This work was supported by the National Research Foundation of Korea (NRF) grant funded by the Korean government [NRF-2017R1A2B3002585 and NRF-2016R1A5A1009405 (M.H.L.); NRF-2021R1A2C3012159 (S.-H.L.)]; the Institute for Basic Science (IBS-R010-A1) in Korea (to M.-H.B.). We thank Professor Youngmin You and Dr. Jiyong Park (IBS) for fruitful discussions on photophysical properties and computational analysis, respectively.

\section{REFERENCES}

(1) Dolmans, D. E.; Fukumura, D.; Jain, R. K., Photodynamic therapy for cancer. Nat. Rev. Cancer 2003, 3, 380-387.

(2) Li, X.; Lovell, J. F.; Yoon, J.; Chen, X., Clinical development and potential of photothermal and photodynamic therapies for cancer. Nat. Rev. Clin. Oncol. 2020, 17, 657-674.

(3) Castano, A. P.; Mroz, P.; Hamblin, M. R., Photodynamic therapy and anti-tumour immunity. Nat. Rev. Cancer 2006, 6, 535-545.

(4) Huang, H.; Banerjee, S.; Qiu, K.; Zhang, P.; Blacque, O.; Malcomson, T.; Paterson, M. J.; Clarkson, G. J.; Staniforth, M.; Stavros, V. G.; Gasser, G.; Chao, H.; Sadler, P. J., Targeted photoredox catalysis in cancer cells. Nat. Chem. 2019, 11, 1041-1048.

(5) Moan, J.; Peng, Q., An outline of the hundred-year history of PDT. Anticancer Res. 2003, 23, 3591-3600.

(6) Kessel, D., Photodynamic therapy: from the beginning. Photodiagnosis Photodyn. Ther. 
2004, 1, 3-7.

(7) Baskaran, R.; Lee, J.; Yang, S. G., Clinical development of photodynamic agents and therapeutic applications. Biomater. Res. 2018, 22, 25.

(8) Moan, J., Porphyrin photosensitization and phototherapy. Photochem. Photobiol. 1986, 43, 681-690.

(9) Gold, M. H.; Goldman, M. P., 5-aminolevulinic acid photodynamic therapy: where we have been and where we are going. Dermatol. Surg. 2004, 30, 1077-1084.

(10) Fritsch, C.; Gardlo, K.; Ruzicka, T., Fluorescence diagnosis in dermatology. In Dermatological phototherapy and photodiagnostic methods, Springer: Berlin, Heidelberg, 2009; pp 387-414.

(11) Alvarado, D. R.; Argyropoulos, D. S.; Scholle, F.; Peddinti, B. S. T.; Ghiladi, R. A., A facile strategy for photoactive nanocellulose-based antimicrobial materials. Green Chem. 2019, 21, 3424-3435.

(12) Peddinti, B. S. T.; Morales-Gagnon, N.; Pourdeyhimi, B.; Scholle, F.; Spontak, R. J.; Ghiladi, R. A., Photodynamic coatings on polymer microfibers for pathogen inactivation: Effects of application method and composition. ACS Appl. Mater. Interfaces 2021, 13, 155-163.

(13) Savelieff, M. G.; Nam, G.; Kang, J.; Lee, H. J.; Lee, M.; Lim, M. H., Development of multifunctional molecules as potential therapeutic candidates for Alzheimer's disease, Parkinson's disease, and amyotrophic lateral sclerosis in the last decade. Chem. Rev. 2019, $119,1221-1322$.

(14) Li, C.; Wang, J.; Liu, L., Alzheimer's therapeutic strategy: photoactive platforms for suppressing the aggregation of amyloid $\beta$ protein. Front. Chem. 2020, 8, 1-6.

(15) Kim, M.; Kang, J.; Lee, M.; Han, J.; Nam, G.; Tak, E.; Kim, M. S.; Lee, H. J.; Nam, E.; Park, J.; Oh, S. J.; Lee, J. Y.; Lee, J. Y.; Baik, M. H.; Lim, M. H., Minimalistic principles for designing small molecules with multiple reactivities against pathological factors in dementia. J. Am. Chem. Soc. 2020, 142, 8183-8193.

(16) Nam, E.; Derrick, J. S.; Lee, S.; Kang, J.; Han, J.; Lee, S. J. C.; Chung, S. W.; Lim, M. H., Regulatory activities of dopamine and its derivatives toward metal-free and metal-induced amyloid- $\beta$ aggregation, oxidative stress, and inflammation in Alzheimer's disease. ACS Chem. Neurosci. 2018, 9, 2655-2666.

(17) Beck, M. W.; Derrick, J. S.; Kerr, R. A.; Oh, S. B.; Cho, W. J.; Lee, S. J.; Ji, Y.; Han, J.; Tehrani, Z. A.; Suh, N.; Kim, S.; Larsen, S. D.; Kim, K. S.; Lee, J. Y.; Ruotolo, B. T.; Lim, M. $\mathrm{H}$., Structure-mechanism-based engineering of chemical regulators targeting distinct pathological factors in Alzheimer's disease. Nat. Commun. 2016, 7, 13115. 
(18) Beck, M. W.; Derrick, J. S.; Suh, J. M.; Kim, M.; Korshavn, K. J.; Kerr, R. A.; Cho, W. J.; Larsen, S. D.; Ruotolo, B. T.; Ramamoorthy, A.; Lim, M. H., Minor structural variations of small molecules tune regulatory activities toward pathological factors in Alzheimer's disease. ChemMedChem 2017, 12, 1828-1838.

(19) Derrick, J. S.; Kerr, R. A.; Nam, Y.; Oh, S. B.; Lee, H. J.; Earnest, K. G.; Suh, N.; Peck, K. L.; Ozbil, M.; Korshavn, K. J.; Ramamoorthy, A.; Prabhakar, R.; Merino, E. J.; Shearer, J.; Lee, J. Y.; Ruotolo, B. T.; Lim, M. H., A redox-active, compact molecule for cross-linking amyloidogenic peptides into nontoxic, off-pathway aggregates: in vitro and in vivo efficacy and molecular mechanisms. J. Am. Chem. Soc. 2015, 137, 14785-14797.

(20) Han, J.; Lee, H. J.; Kim, K. Y.; Lee, S. J. C.; Suh, J. M.; Cho, J.; Chae, J.; Lim, M. H., Tuning structures and properties for developing novel chemical tools toward distinct pathogenic elements in Alzheimer's disease. ACS Chem. Neurosci. 2018, 9, 800-808.

(21) Ishida, Y.; Tanimoto, S.; Takahashi, D.; Toshima, K., Photo-degradation of amyloid $\beta$ by a designed fullerene-sugar hybrid. Med. Chem. Commun. 2010, 1, 212-215.

(22) Lee, B. I.; Lee, S.; Suh, Y. S.; Lee, J. S.; Kim, A. K.; Kwon, O. Y.; Yu, K.; Park, C. B., Photoexcited porphyrins as a strong suppressor of $\beta$-amyloid aggregation and synaptic toxicity. Angew. Chem. Int. Ed. 2015, 54, 11472-11476.

(23) Kang, J.; Lee, S. J.; Nam, J. S.; Lee, H. J.; Kang, M. G.; Korshavn, K. J.; Kim, H. T.; Cho, J.; Ramamoorthy, A.; Rhee, H. W.; Kwon, T. H.; Lim, M. H., An iridium(III) complex as a photoactivatable tool for oxidation of amyloidogenic peptides with subsequent modulation of peptide aggregation. Chem. Eur. -J. 2017, 23, 1645-1653.

(24) Leung, C. H.; Zhong, H. J.; Chan, D. S. H.; Ma, D. L., Bioactive iridium and rhodium complexes as therapeutic agents. Coord. Chem. Rev. 2013, 257, 1764-1776.

(25) Man, B. Y.-W.; Chan, H.-M.; Leung, C.-H.; Chan, D. S.-H.; Bai, L.-P.; Jiang, Z.-H.; Li, H.-W.; Ma, D.-L., Group 9 metal-based inhibitors of $\beta$-amyloid (1-40) fibrillation as potential therapeutic agents for Alzheimer's disease. Chem. Sci. 2011, 2, 917-921.

(26) Wong, C. Y.; Chung, L. H.; Lu, L. H.; Wang, M.; He, B. Y.; Liu, L. J.; Leung, C. H.; Ma, D.-L., Dual inhibition and monitoring of beta-amyloid fibrillation by a luminescent iridium(III) complex. Curr. Alzheimer Res. 2015, 12, 439-444.

(27) Gomes, L. M. F.; Bataglioli, J. C.; Storr, T., Metal complexes that bind to the amyloid- $\beta$ peptide of relevance to Alzheimer's disease. Coord. Chem. Rev. 2020, 412, 213255.

(28) Bataglioli, J. C.; Gomes, L. M. F.; Maunoir, C.; Smith, J. R.; Cole, H. D.; McCain, J.; Sainuddin, T.; Cameron, C. G.; McFarland, S. A.; Storr, T., Modification of amyloid-beta peptide aggregation via photoactivation of strained Ru(II) polypyridyl complexes. Chem. Sci. 
2021, 12, 7510-7520.

(29) Chung, Y. J.; Lee, C. H.; Lim, J.; Jang, J.; Kang, H.; Park, C. B., Photomodulating carbon dots for spatiotemporal suppression of Alzheimer's $\beta$-amyloid aggregation. ACS Nano 2020, 14, 16973-16983.

(30) Kim, K.; Lee, S. H.; Choi, D. S.; Park, C. B., Photoactive bismuth vanadate structure for light-triggered dissociation of Alzheimer's $\beta$-amyloid aggregates. Adv. Funct. Mater. 2018, 28, 1802813.

(31) Lee, J. S.; Lee, B. I.; Park, C. B., Photo-induced inhibition of Alzheimer's $\beta$-amyloid aggregation in vitro by rose bengal. Biomaterials 2015, 38, 43-49.

(32) Taniguchi, A.; Sasaki, D.; Shiohara, A.; Iwatsubo, T.; Tomita, T.; Sohma, Y.; Kanai, M., Attenuation of the aggregation and neurotoxicity of amyloid- $\beta$ peptides by catalytic photooxygenation. Angew. Chem. Int. Ed. 2014, 53, 1382-1385.

(33) Ni, J.; Taniguchi, A.; Ozawa, S.; Hori, Y.; Kuninobu, Y.; Saito, T.; Saido, T. C.; Tomita, T.; Sohma, Y.; Kanai, M., Near-infrared photoactivatable oxygenation catalysts of amyloid peptide. Chem 2018, 4, 807-820.

(34) Lee, B. I.; Suh, Y. S.; Chung, Y. J.; Yu, K.; Park, C. B., Shedding light on Alzheimer's $\beta$ amyloidosis: photosensitized methylene blue inhibits self-assembly of $\beta$-amyloid peptides and disintegrates their aggregates. Sci. Rep. 2017, 7, 7523.

(35) Pardridge, W. M., Drug transport across the blood-brain barrier. J. Cereb. Blood Flow Metab. 2012, 32, 1959-1972.

(36) Zheng, W.; Aschner, M.; Ghersi-Egea, J. F., Brain barrier systems: a new frontier in metal neurotoxicological research. Toxicol. Appl. Pharmacol. 2003, 192, 1-11.

(37) Egorova, K. S.; Ananikov, V. P., Toxicity of metal compounds: knowledge and myths. Organometallics 2017, 36, 4071-4090.

(38) Win-Shwe, T. T.; Fujimaki, H., Nanoparticles and neurotoxicity. Int. J. Mol. Sci. 2011, 12, 6267-6280.

(39) Vutskits, L.; Briner, A.; Klauser, P.; Gascon, E.; Dayer, A. G.; Kiss, J. Z.; Muller, D.; Licker, M. J.; Morel, D. R., Adverse effects of methylene blue on the central nervous system. Anesthesiology 2008, 108, 684-692.

(40) Frank, M.; Ahrens, J.; Bejenke, I.; Krick, M.; Schwarzer, D.; Clever, G. H., Light-induced charge separation in densely packed donor-acceptor coordination cages. J. Am. Chem. Soc. 2016, 138, 8279-8287.

(41) Lee, W.; Jung, S.; Kim, M.; Hong, S., Site-selective direct C-H pyridylation of unactivated alkanes by triplet excited anthraquinone. J. Am. Chem. Soc. 2021, 143, 3003-3012. 
(42) Kawaai, K.; Yamaguchi, T.; Yamaguchi, E.; Endo, S.; Tada, N.; Ikari, A.; Itoh, A., Photoinduced generation of acyl radicals from simple aldehydes: access to 3-acyl-4arylcoumarin derivatives, and evaluation of their antiandrogenic activities. J. Org. Chem. 2018, 83, 1988-1996.

(43) Yadav, R. K.; Baeg, J. O.; Oh, G. H.; Park, N. J.; Kong, K. J.; Kim, J.; Hwang, D. W.; Biswas, S. K., A photocatalyst-enzyme coupled artificial photosynthesis system for solar energy in production of formic acid from $\mathrm{CO}_{2}$. J. Am. Chem. Soc. 2012, 134, 11455-11461.

(44) Reece, S. Y.; Seyedsayamdost, M. R.; Stubbe, J.; Nocera, D. G., Photoactive peptides for light-initiated tyrosyl radical generation and transport into ribonucleotide reductase. J. Am. Chem. Soc. 2007, 129, 8500-8509.

(45) Ou, H. D.; Phan, S.; Deerinck, T. J.; Thor, A.; Ellisman, M. H.; O'Shea, C. C., ChromEMT: Visualizing $3 \mathrm{D}$ chromatin structure and compaction in interphase and mitotic cells. Science 2017, 357, eaag0025.

(46) Chen, G. F.; Xu, T. H.; Yan, Y.; Zhou, Y. R.; Jiang, Y.; Melcher, K.; Xu, H. E., Amyloid beta: structure, biology and structure-based therapeutic development. Acta. Pharmacol. Sin. 2017, 38, 1205-1235.

(47) Montoya, S. C.; Comini, L. R.; Sarmiento, M.; Becerra, C.; Albesa, I.; Arguello, G. A.; Cabrera, J. L., Natural anthraquinones probed as Type I and Type II photosensitizers: singlet oxygen and superoxide anion production. J. Photochem. Photobiol. B 2005, 78, 77-83.

(48) Gollnick, K.; Held, S.; Martire, D. O.; Braslavsky, S. E., Hydroxyanthraquinones as sensitizers of singlet oxygen reactions - quantum yields of triplet formation and singlet oxygen generation in acetonitrile. J. Photochem. Photobiol. A 1992, 69, 155-165.

(49) Bredas, J. L.; Beljonne, D.; Coropceanu, V.; Cornil, J., Charge-transfer and energy-transfer processes in p-conjugated oligomers and polymers: a molecular picture. Chem. Rev. 2004, 104, 4971-5004.

(50) Mohammed, O. F.; Xiao, D.; Batista, V. S.; Nibbering, E. T., Excited-state intramolecular hydrogen transfer (ESIHT) of 1,8-dihydroxy-9,10-anthraquinone (DHAQ) characterized by ultrafast electronic and vibrational spectroscopy and computational modeling. J. Phys. Chem. A 2014, 118, 3090-3099.

(51) Flom, S. R.; Barbara, P. F., Proton transfer and hydrogen bonding in the internal conversion of S1 anthraquinones. J. Phys. Chem. 2002, 89, 4489-4494.

(52) Choi, J. R.; Jeoung, S. C.; Cho, D. W., Time-resolved anisotropy study on the excited-state intramolecular proton transfer of 1-hydroxyanthraquinone. Bull. Korean Chem. Soc. 2003, $24,1675-1679$. 
(53) Suess, C. J.; Hirst, J. D.; Besley, N. A., Quantum chemical calculations of tryptophan -> heme electron and excitation energy transfer rates in myoglobin. J. Comput. Chem. 2017, 38, 1495-1502.

(54) Subotnik, J. E.; Vura-Weis, J.; Sodt, A. J.; Ratner, M. A., Predicting accurate electronic excitation transfer rates via marcus theory with Boys or Edmiston-Ruedenberg localized diabatization. J. Phys. Chem. A 2010, 114, 8665-8675.

(55) Sherbrook, E. M.; Jung, H. M.; Cho, D.; Baik, M. H.; Yoon, T. P., Bronsted acid catalysis of photosensitized cycloadditions. Chem. Sci. 2020, 11, 856-861.

(56) Miliani, C.; Romani, A.; Favaro, G., Acidichromic effects in 1,2-di- and 1,2,4-trihydroxyanthraquinones. A spectrophotometric and fluorimetric study. J. Phys. Org. Chem. 2000, 13, 141-150.

(57) Pareras, G.; Palusiak, M.; Duran, M.; Sola, M.; Simon, S., Tuning the strength of the resonance-assisted hydrogen bond in o-hydroxybenzaldehyde by substitution in the aromatic ring. J. Phys. Chem. A 2018, 122, 2279-2287.

(58) Suzuki, K.; Kobayashi, A.; Kaneko, S.; Takehira, K.; Yoshihara, T.; Ishida, H.; Shiina, Y.; Oishi, S.; Tobita, S., Reevaluation of absolute luminescence quantum yields of standard solutions using a spectrometer with an integrating sphere and a back-thinned CCD detector. Phys. Chem. Chem. Phys. 2009, 11, 9850-9860.

(59) Wessels, J. M.; Foote, C. S.; Ford, W. E.; Rodgers, M. A., Photooxidation of tryptophan: $\mathrm{O}_{2}\left({ }^{1} \Delta_{\mathrm{g}}\right)$ versus electron-transfer pathway. Photochem. Photobiol. 1997, 65, 96-102.

(60) Nam, J. S.; Kang, M. G.; Kang, J.; Park, S. Y.; Lee, S. J.; Kim, H. T.; Seo, J. K.; Kwon, O. H.; Lim, M. H.; Rhee, H. W.; Kwon, T. H., Endoplasmic reticulum-localized iridium(III) complexes as efficient photodynamic therapy agents via protein modifications. J. Am. Chem. Soc. 2016, 138, 10968-10977.

(61) Latour, V.; Pigot, T.; Simon, M.; Cardy, H.; Lacombe, S., Photo-oxidation of di-n-butylsulfide by various electron transfer sensitizers in oxygenated acetonitrile. Photochem. Photobiol. Sci. 2005, 4, 221-229.

(62) Dhakal, P.; Kuzyk, M. G., Molecular structure and reversible photodegradation in anthraquinone dyes. J. Photochem. Photobiol. A 2016, 328, 66-76.

(63) Ni, W.; Chen, W.; Lu, Y., Emerging findings into molecular mechanism of brain metastasis. Cancer Med. 2018, 7, 3820-3833.

(64) Avdeef, A.; Bendels, S.; Di, L.; Faller, B.; Kansy, M.; Sugano, K.; Yamauchi, Y., PAMPAcritical factors for better predictions of absorption. J. Pharm. Sci. 2007, 96, 2893-2909.

(65) Di, L.; Kerns, E. H.; Fan, K.; McConnell, O. J.; Carter, G. T., High throughput artificial 
membrane permeability assay for blood-brain barrier. Eur. J. Med. Chem. 2003, 38, 223232.

(66) Mormino, E. C.; Kluth, J. T.; Madison, C. M.; Rabinovici, G. D.; Baker, S. L.; Miller, B. L.; Koeppe, R. A.; Mathis, C. A.; Weiner, M. W.; Jagust, W. J., Episodic memory loss is related to hippocampal-mediated beta-amyloid deposition in elderly subjects. Brain 2009, 132, 1310-1323.

(67) Reilly, J. F.; Games, D.; Rydel, R. E.; Freedman, S.; Schenk, D.; Young, W. G.; Morrison, J. H.; Bloom, F. E., Amyloid deposition in the hippocampus and entorhinal cortex: quantitative analysis of a transgenic mouse model. Proc. Natl. Acad. Sci. U. S. A. 2003, 100, 4837-4842.

(68) Wengenack, T. M.; Whelan, S.; Curran, G. L.; Duff, K. E.; Poduslo, J. F., Quantitative histological analysis of amyloid deposition in Alzheimer's double transgenic mouse brain. Neuroscience 2000, 101, 939-944.

(69) Kim, K. S.; Miller, D. L.; Sapienza, V. J.; Chen, C. M. J.; Bai, C.; Grundke-lqbal, I.; Currie, C. J.; Wisniewski, H. M., Production and characterization of monoclonal antibodies reactive to synthetic cerebrovascular amyloid peptide. Neurosci. Res. Commun. 1988, 2, 121-130.

(70) Kim, K. S.; Wen, G. Y.; Bancher, C.; Chen, C. M. J.; Sapienza, V. J.; Hong, H.; Wisniewski, H. M., Detection and quantitation of amyloid beta-peptide with 2 monoclonal antibodies. Neurosci. Res. Commun. 1990, 7, 113-122.

(71) Kayed, R.; Head, E.; Thompson, J. L.; McIntire, T. M.; Milton, S. C.; Cotman, C. W.; Glabe, C. G., Common structure of soluble amyloid oligomers implies common mechanism of pathogenesis. Science 2003, 300, 486-489.

(72) Kelenyi, G., Thioflavin S fluorescent and Congo red anisotropic stainings in the histologic demonstration of amyloid. Acta Neuropathol. 1967, 7, 336-348.

(73) Urbanc, B.; Cruz, L.; Le, R.; Sanders, J.; Ashe, K. H.; Duff, K.; Stanley, H. E.; Irizarry, M. C.; Hyman, B. T., Neurotoxic effects of Thioflavin S-positive amyloid deposits in transgenic mice and Alzheimer's disease. Proc. Natl. Acad. Sci. U. S. A. 2002, 99, 13990-13995.

(74) Mora, A. K.; Khan, S.; Patro, B. S.; Nath, S., Is DAPI assay of cellular nucleic acid reliable in the presence of protein aggregates? Chem. Commun. 2020, 56, 13844-13847.

(75) Simard, A. R.; Soulet, D.; Gowing, G.; Julien, J. P.; Rivest, S., Bone marrow-derived microglia play a critical role in restricting senile plaque formation in Alzheimer's disease. Neuron 2006, 49, 489-502.

(76) Lee, S. J.; Nam, E.; Lee, H. J.; Savelieff, M. G.; Lim, M. H., Towards an understanding of amyloid-beta oligomers: characterization, toxicity mechanisms, and inhibitors. Chem. Soc. Rev. 2017, 46, 310-323. 
(77) Benilova, I.; Karran, E.; De Strooper, B., The toxic Abeta oligomer and Alzheimer's disease: an emperor in need of clothes. Nat. Neurosci. 2012, 15, 349-357.

(78) Lorenzo, A.; Yankner, B. A., Amyloid fibril toxicity in Alzheimer's disease and diabetes. Ann. N. Y. Acad. Sci. 1996, 777, 89-95.

(79) Tsai, J.; Grutzendler, J.; Duff, K.; Gan, W. B., Fibrillar amyloid deposition leads to local synaptic abnormalities and breakage of neuronal branches. Nat. Neurosci. 2004, 7, 11811183.

(80) Chen, W. T.; Lu, A.; Craessaerts, K.; Pavie, B.; Sala Frigerio, C.; Corthout, N.; Qian, X.; Lalakova, J.; Kuhnemund, M.; Voytyuk, I.; Wolfs, L.; Mancuso, R.; Salta, E.; Balusu, S.; Snellinx, A.; Munck, S.; Jurek, A.; Fernandez Navarro, J.; Saido, T. C.; Huitinga, I.; Lundeberg, J.; Fiers, M.; De Strooper, B., Spatial transcriptomics and in situ sequencing to study Alzheimer's disease. Cell 2020, 182, 976-991. 